\title{
Exploring DIY Practices of Complex Home Technologies
}

\author{
CORINA SAS, School of Computing and Communications; Institute for Social Future, Lancaster University \\ CARMAN NEUSTAEDTER, School of Interactive Arts and Technology, Simon Fraser University
}

\begin{abstract}
We are surrounded by increasingly complex networks of smart objects, yet our understanding and attachment to them is rather limited. One way to support stronger end users' engagement with such complex technologies is by involving them in the design process and, with the advent of Arduino prototyping platform, even in their making. While DIY practice offers the potential for stronger user engagement with physical artifacts, we know little about end users' DIY practice of making complex electronic technologies and their potential to ensure engagement with such devices. In this paper, we report on interviews with 18 participants from two green communities who built and used an open source DIY energy monitor, with the aim to explore the end users DIY practices of making such complex electronic devices. Findings indicate four key qualities of DIY monitors: transparent modularity, open-endedness, heirloom and disruptiveness, and how they contribute to more meaningful engagement with the DIY monitors, elevating them from the status of unremarkable objects to that of things. We conclude with three implications for design for supporting end user development of complex electronic DIY: designing transparent open hardware technologies, standardizing communication protocols for the current and future DIY of IoT; and deliberately calling for personal investment and labor in the assembling of DIY kits.
\end{abstract}

Categories and Subject Descriptors: H.5.m. Information interfaces and presentation (e.g., HCI): Miscellaneous.

General Terms: Design

Additional Key Words: DIY practices; complex technologies; end user development; emotional engagement.

\section{INTRODUCTION}

We live rich digital lives, increasingly surrounded by objects which can sense and respond intelligently to our behaviors and desires. Whether we wear them on our bodies, carry them in our pockets, or deploy them in our homes and cities, these networks of smart objects are increasingly interconnected into the fabric of the Internet of Things (IoT) [Marenko, 2014b]. The complexity of everyday technologies such as mobile phones [Mellis and Buechley, 2014], laptops [Rosner and Ames, 2014], wearables [Sas et al., 2013; Sas and Chopra, 2015], or home technologies [Erickson et al., 2013] often comes at the price of casting users as passive actors rather than proactive in their engagement with them [Rogers, 2006]. As a result, people seldom develop rich engagement and attachment to them, becoming merely passive consumers with limited understanding of how technologies work [Cooper, 2004; Mellis and Buechley, 2014] or can be fixed [Wakkary et al., 2013], and more inclined to dispose of broken ones [Pierce and Paulos, 2012; Strengers, 2011]. These limitations are further heightened in the context of IoT because of the added complexity of multiple devices and their interconnectivity. One way of addressing such challenges is by new approaches to end users' engagement in the development process. For example, previous work has shown that DIY practices motivate people to highly value and develop attachment to their own handmade physical artifacts [Shove, 2007], which Norton [2011] coined as IKEA effect.

ACM copyright: ACM holds the copyright on the work. This is the historical approach.

$\square$ License: The author(s) retain copyright, but ACM receives an exclusive publication license.

$\square$ Open Access: The author(s) wish to pay for the work to be open access. The additional fee must be paid to ACM. 
We know however little about the potential of electronic DIY practice in supporting higher levels of engagement and attachment to complex technologies. Aligned with this thesis, in their manifesto for democratizing end users' access to IoT, De Roeck and colleagues [2012] also proposed leveraging the emerging electronic DIY practices. They proposed a framework for a creation platform for DIY IoT applications including basic hardware sensors and actuators to support specific functionalities in given contexts. De Roeck and colleagues [2012] argue that, through DIY of IoT applications, end users will become makers or so called prosumers of IoT smart objects and networked technologies. On the one hand, this marks a much needed shift in the end user development (EUD) research agenda, from its previous limited focus on desktop applications [Paternò, 2013] towards the development of domain specific meta-design tools [Lieberman et al., 2006]. On the other hand, the manifesto challenges the DIY communities, and in particular open hardware ones, to explore new methods and tools for supporting the participation of end users with limited technical skills. Open hardware consists of technologies which end users can make, alter and use because their design and software are publically available.

Noticeable success over the last decade has been the growth of open hardware prototyping platforms [Hertz, 2011; Kuznetsov and Paulos, 2010] which are already changing the practice of technology production particularly in hackers' communities [Lindtner et al., 2014]. However, we know little about the end users' DIY practice of making complex devices.

In this paper we explore a specific home technology, namely an open source DIY energy monitor (further referred to as DIY monitor), and two green communities: an online community which has developed the DIY monitor kit and adopted it, and a local community which also adopted it. The rationale for focusing on an energy monitor and its DIY practices is threefold. First, energy monitors are good illustration of the concept of IoT, especially when it could be extended with additional sensors. Moreover, they are deployed within the home, enabling thus the exploration of the home infrastructure and its value in the domestication of the DIY monitor and potentially of its network of smart objects. A focus on energy monitors also addresses the recent call for engaging end user development research into the DIY sustainability agenda [Boden at al., 2013]. Finally, unlike most previous HCI studies of electronic DIY practices targeting non-electronic or simple electronic technologies, energy monitors are complex devices.

In this paper, we report interviews with 18 participants from two communities of end users engaged in high tech DIY practices of making complex devices such as energy monitors. We explored their experience of assembling and using the DIY monitors, and report participants' appreciation for the care and labor that goes into the creation of the DIY kit, their increased understanding of how the DIY monitor works, appreciation of the energy savings and DIY monitors' ability to resist obsolescence. We identified four specific qualities of DIY kits and DIY monitors: transparent modularity, open-endedness, heirloom, and disruptiveness and described how these qualities contribute to a more meaningful engagement with complex devices, i.e. DIY monitors as things. Study findings also suggest three implications that may support the end user development of complex DIY technologies. These include designing transparent complex technologies which can be tinkered with (i.e., played, repaired, or improved), and transparent DIY kits for making them; standardizing communication protocols for the current and future DIY of IoT; and deliberately calling for personal labor in the assembling of DIY kits, which in turn may support stronger understanding of their inner workings, engagement and attachment. 


\section{RELATED WORK}

Our discussion involves three levels: DIY kit, DIY monitor, and the home infrastructure where it is deployed. Hence, the organization of the literature review reflects this. We draw from the emerging end user development work on open hardware and IoT and their design tools, the growing body of HCI studies on DIY practices, and HCI work on technology domestication and its impact on home infrastructure.

\subsection{End User Development for Open Hardware}

In a review of the third wave DIY of today's informational society, Fox [2014] identified the value of open knowledge for end user development and its prosumption of complex physical goods from 3D printouts to embedded microelectronics. He also mentioned the lack of domain specific DIY kits to support prosumption of electronic devices. This contrasts with the abundance of such tools in the previous, industrial DIY wave, such as flatpack furniture kits with pre-assembled components and standardized instructions. This suggests the value of exploring alternative DIY kits to support end user development of IoT. However, research into end user development has particularly highlighted the challenges of developing for the IoT. Key challenges for developing not only software but also hardware components include integrating the digital with the physical, supporting interaction design, and accounting for the socio-technical context [Tetteroo et al., 2013]. Tetteroo and colleagues [2013] also argued that such challenges can be addressed through innovative toolkits and in particular toolkits for meta-design defined as tools which provide end users with opportunities to extend their design outcomes according to their needs.

An acclaimed starting point for the end user development for IoT is the existing open source tools and platforms supporting the physical making of smart objects. Among those, Arduino is particular popular. An open source electronic platform for general purpose prototyping, benefiting from modular hardware, software libraries and extensive documentation as well as community support, Arduino has started to empower novice end users by enabling them to create their own devices [Brown et al., 2012]. Previous work has shown that Arduino prototyping platform allows designers to directly experiment with the physicality of hardware components [Mellis and Buechley, 2014] which talk back to them. Schön [1992] called this a material situation where designers converse with, and learn to sensorially appreciate design materials by constructing and reconstructing design outcomes.

A particularly relevant theory for the exploration of end user development for electronic DIY is the morphogenetic model which has emerged as a critique of the dominating model of design [Ingold, 2010] that emphasizes the authority of the designer and the separation between the design of ideas and the making of objects. This separation leads to the production of complete and static objects which cannot evolve [Marenko, 2014a]. Most of our everyday objects are outcomes of this dominating model as they are mass produced through automatic processes which prioritize form over matter or the blueprint of design over the passivity of materials [DeLanda, 1992]. In addition, this dominant model fails to account for properties of the material and arguably, material's active role in guiding the maker towards unplanned design trajectories [Devendorf and Ryokai, 2015]. To challenge this dominating view and address its limitation, Deleuze and Guattari [1988] have advanced the morphogenetic model arguing that the design authority should be 
shared by both the maker and the material which is conceptualized as active, generative and self-organizing, speaking back to the maker [Ingold, 2013].

Morphogenetic model allows for form finding (rather than form forming) of objects which emerge from the situated interplay and experimentation of maker with material [Devendorf and Ryokai, 2015]. Rather than being predetermined, such design outcome emerges through an embodied, intuition-driven and nonlinear process as a dynamic object, changing in response to the endless variation of matter [Marenko, 2014a]. To illustrate this, Ingold [2007] described carpenter's ongoing feeling and surrendering to the grain of the wood, which he called the textility of the making, or the "tactile and sensuous knowledge of material's becoming, and following its course through rhythmical improvisation" [Ingold, 2010, p. 29]. Ingold described such outcome as a fluid work-in-progress or a thing, never completed but holding the potential of many possible becomings. This conceptualization of design outcome borrows from Heidegger's [1971] distinction between objects and things where the former are unremarkable until they break, while the latter offer opportunities for affective encounters which move us [Ingold, 2012].

A useful framework for reflecting on people's relationship and attachment to artifacts is Thing theory, proposed by Brown [2001], which extends the distinction between objects and things, while offering a powerful lens to explore the physical qualities of software and hardware technologies. It advances a conceptualization of objects as unremarkable stuff receded in the background of mundane interactions. Objects do step into the foreground of our attention but only when they break, become obsolete, or when take on additional aesthetic or spiritual value [Breitbach, 2011]. At such critical moments, objects as ultimate commodities become things pointing to the object-subject relationship.

Notoriously difficult to define as they lay between the material and ideational world, things "talk" [Plotz, 2006] inviting reflection on themselves, and supporting emotional connection as meaningful possessions. Brown [2001] also points to the duality between objects and things: the abundance of everyday objects, which we routinely and often mindlessly interact with, contrasts with the scarcity of things; yet most objects hold the potential of becoming things when our relationship with them is re-considered. Brown [2001] illustrated these concepts in relation to photographs; most of which are everyday commodities (objects) while a few are treasured possessions (things) holding a sensuous, metaphysical or magic presence. While objects emerge from things, things can exist both before, and after objects, as amorphous matter from which objects materialize and where objects return at the end of their existence [Breitbach, 2011].

In a reflection on Arduino's potential to enable the understanding of the inner working of technologies, Hertz [2011] defined blackboxing as a requirement of advanced technology to deliberately hide its complexity which otherwise would overburden users. It has been also argued that blackboxing is rooted in manufacturers' effort to inhibit infringement, by imposing limitations on the user's agency of tinkering with technology [Gillespie, 2006], and that it can protect those lacking such competences [Wakkary et al., 2013]. While it ensures a smooth inputoutput functionality, blackboxing comes at the cost, as people lack the understanding of how technology works or can be fixed, which renders it obsolete at an accelerated rate. Hertz [2011] also described the reverse of blackboxing, which he called depunctualization and consists of breaking apart a device into its block components. He referred to Arduino's potential to support depunctualization by enabling people to 
understand the building block of electronics and to experiment directly with the inner working of technology. Previous findings have also shown that novice Arduino users may still need to engage in basic learning about coding and engineering [Lagerström et al., 2014], particularly if they wish to develop complex technologies.

For defining DIY kit, we adopt Hermans' definition as [2014, p. 17] "an assembly of tools aimed at a particular purpose". In an effort to understand the design of DIY kits and their different types, he identified a design space along two dimensions: designers' authority expressed through specific DIY guidance, and user's autonomy to create something new as undetermined outcomes.

By analyzing four DIY kits for content management, music production, jewelry and furniture design, he developed a lay design model consisting of restrictive design, open design, technique, and exploratory design. These types of DIY kits can be mapped on a continuum of end users, from adapter, maker, and explorer to creator, each requiring increased imagination and responsibility as passive consumer develops into professional designer. This typology offers a useful lens into two dimensions of DIY kits: instructions and indeterminacy of the outcome, and their impact on the levels of design novelty. Most DIY kits are exemplar of restrictive design as they consist of components with clear instructions for assembling into a predetermined outcome such as IKEA kits consisting of flat packaged detachable components for easy to assemble home furniture; an innovative business model that has made IKEA the largest furniture retailer in the world. In contrast, exploratory design is not constrained by determinate outcome and instructions. A similar distinction has been made between pro-active DIY which is creative and self-directed, and reactive $D I Y$ which is predetermined by kits and instructions [Atkinson, 2006]. This distinction is grounded on the historic view of DIY movement which gained momentum in the post-war context ensuring two DIY outcomes: the making of domestic objects, i.e., clothes, soft furnishings, furniture, boats; and the improvement of the home through building work, electrical work, plumbing, or gardening. Another historic exploration of DIY, Gelber [1999] cited by Mellis [2015] identified various materials of DIY kits such as wood, leather, or plastic components which get assembled for the making of domestic objects from wallets to wooden boats.

To summarize, the advent of open source hardware platforms for generic prototyping offers a springboard for the development of domain specific electronic DIY kits. The outstanding challenge here is to understand and harness the best qualities of such DIY kits, so that they can be used to support the meta-design of complex electronic technologies which could adapt to people's ongoing needs. In this way, end users can engage not just in restrictive design, but also in open or exploratory design.

\subsection{DIY Practices in $\mathrm{HCl}$}

The last fifteen years have witnessed a growing interest in the DIY practices within local communities of craft enthusiasts, most tailored towards green or sustainable living. These practices have started to engage HCI scholars interested in laying out the foundation for practice-based approaches to HCI research and design [Pierce et al., 2013]. This work has been theoretically framed, among others, by Reckwitz's [2002] definition of practice as intersecting bodily activities on physical objects, and Shove's [2007] phenomenological approach emphasizing materials, meanings and competences. Most research in this area has focused on the DIY practices of making, and repairing of both nonelectronic and electronic devices in the maker movement. 
Studies have explored the practices of making physical objects within local green communities [Wakkary et al., 2013]. Green communities have engaged predominantly in DIY for sustainable living practices such as gardening and food growing, as well as household product repair, reuse and recycle, or home improvement for limiting environmental impact [van Dam et al., 2010]. Wakkary and colleagues [2013] looked at the making and repairing of everyday objects and green DIY practices, showing the prevalence of physical objects and people's enjoyment of handcraft, while Strengers [2011] highlighted the autotelic nature of DIY practice, the labor invested, and the competences developed throughout.

Other bodies of work have explored the making of sensors. For example, Kuznetsov and colleagues [2010] explored innovative materials as tools for environmental sensing and showed that with appropriate guidance in workshops facilitated by researchers, people are able to make simple DIY technologies. They developed and evaluated DIY kits enabling non experts to assemble, both without [Kuznetsov et al., 2013; Kuznetsov et al., 2014] and with electronics [Kuznetsov et al., 2011]. In a recent work [Kuznetsov et al., 2014], they describe the design and deployment of a low cost, paper based sensor for pollution, showing the value of tangible interaction in changing assumptions about environmental pollution.

Another body of HCI work has explored high tech DIY - the practice of making or repairing complex electronic devices, such as mobile phones [Mellis and Buechley, 2014] or laptops [Rosner and Ames, 2014]. Arguing for a rather complex relationship that people have with electronic devices, Blevis and Stolterman [2007] discussed the quality of cherished artifacts as ensouled things which are loved and cared for, and seldom discarded. Mellis and Buechley [2014] have also shown that with appropriate guidance during researcher-led workshops, people can successfully build complex electronic devices such as cell phones. Such work emphasizes the importance of academic-led development of DIY tools and of facilitating DIY workshops. Wakkary and colleagues [2013] found that people seldom repair electronic objects, mostly because this requires sophisticated skills.

Similarly, in an exploration of home automation technologies, Strengers [2011] looked into the DIY practice of repair and maintenance of complex technologies, showing that most people dispose of broken appliances rather than repairing them. While left to their own devices people appear to lack engagement in spontaneous high tech DIY [Abrahamse and Steg, 2009]. Blevis and Stolterman [2007] also showed that unlike physical objects, complex electronic devices seldom acquire ensoulment status, and identified five relevant resource-conserving themes: the need to reduce the use of disposable materials, and energy use, the need of increasing the feeling of ownership of shared public resources, the need of renewing digital devices by adding new ones instead of discarding the old ones, and the need to foster richer user attachment through material qualities preserving sentiments and histories, i.e., expressive engagement. Blevis and Stolterman [2007] also noted the limited HCI work exploring the qualities of electronic devices contributing to ensoulement, and how these may be used by designers to develop enduring products.

Apart from the growth of DIY communities, the last decade has also seen a shift in maker communities from open software to open hardware, underpinned by similar values of social activism. With the emergence of HCI research into the practices of open source hardware communities [Kuznetsov and Paulos, 2010], we have seen hackers' practices framed as sites for innovation, and exploration of new models of entrepreneurship particularly in Asian context [Lindtner et al., 2014]. DIY practices 
have also been explored beyond the developed contexts, with findings highlighting its culturally sensitive aspects. For instance, efforts have been made to integrate the exploration of maker movement with ICT4D agenda with a focus on 3D printing of prostheses or educational models in Palestine [Stickel et al., 2015]. In their critique of the utopian DIY vision for democratizing technology production, Lindtner and colleagues [2016] call for HCI engagement with both the technical innovation and socio-political contexts; their study of the maker movement in China and Taiwan argue for the value of a HCI research agenda towards collective empowerment through DIY. HCI interest in the democratization of open source technology production have focused also on blockchain technology [Sas and Khairuddin, 2015; Khairuddin et al., 2016] particularly in Malaysia [Sas and Khairuddin, 2017].

Findings have also shown that people develop an attachment towards the artifacts generated through DIY practices [Kuznetsov and Paulos, 2010]. Reflecting on the open hardware practices, Hertz [2011] identified a pleasure-oriented DIY culture and its benefit in supporting people to express themselves, experiment, and engage with an increasingly digital world.

Another area of growing interest in HCI are naturally occurring repair practices [Rosner and Ames, 2014] targeting artifacts from everyday objects [Wakkary et al., 2013] to electronic appliances [Strengers, 2011; van Dam et al., 2010]. Findings have consistently shown that because of limited expertise [Holmer et al., 2015], people often fail to repair electronic devices [Wakkary et al., 2013], and end up disposing their broken appliances [Pierce and Paulos, 2012; Strengers, 2011].

Rosner and Ames [2014] have explored approaches to breakdown and repair by focusing on children's laptops in Paraguay. Laptops were repaired-not by the children owning them-but by skilled teacher trainers and their technical team from a national organization. Depending on the complexity, repairs were either done on or off site. Studies of urban Fixit Clinics in California showed that despite organisers' efforts to support participatory repair practices, most repairs were made by the coaches of the clinic without owners' involvement or understanding; independent repair work performed at home was rare [Rosner and Ames, 2014]. Practices such as improvement and recycling have been less explored [Holmer et al., 2015]. Exceptions include home improvement for limiting environmental impact [Shove, 2007; Woodruff et al., 2008] and cell phone recycling [Burrell, 2012].

Another example of high tech technology relevant for green communities is energy monitor. Apart from the findings showing that people are more likely to dispose of such complex devices rather than repairing them [Cooper, 2004], there has been limited exploration into the DIY making practices of monitors. Most HCI work on energy monitoring has focused on commercial monitors or research prototypes [Erickson et al., 2013; Fischer, 2008; Kuznetsov et al., 2014; van Dam et al., 2010] with findings suggesting that energy savings are neither large [Fischer, 2008], nor lasting [van Dam et al., 2010]. This may be due to people's difficulties of incorporating conservational practices into daily routines, and insufficient understanding of the monitors, operated through superficial functional models [Caillot and Nguyen-Xuan, 1995; Neustaedter et al., 2013; Pierce et al., 2010], which may lead to weak attachment and engagement [Erickson et al., 2013; Strengers, 2011; Strengers, 2013; Woodruff et al., 2008].

To conclude, most HCI work on DIY practices have shown that people get pleasure from hands-on tinkering but engage mostly in the making and repairing of 
nontechnical household items rather than complex electronic devices. With a few exceptions of studies on hackers' spaces, electronic making has been mostly explored through researchers-led workshops and DIY kits, showing that with sufficient scaffolding novice people successfully assemble the kits. An outstanding challenge here is that we know little about the qualities of such DIY kits, particularly for high tech DIY. The exploration of DIY practices has also extended beyond the developed world, to other cultural contexts such as Asia and South America.

\subsection{Home Technologies: Technology Domestication}

We now review HCI work on deploying technologies in the home. The value of physicality of everyday technologies has been previously highlighted, particularly with respect to spatial and social arrangements [Dourish et al., 2010; Tolmie et al., 2010]. Unlike most DIY practices of making, focusing on personal devices [Mellis and Buechley, 2014], the making of energy monitors as family home devices has been less explored. Yet such explorations can offer insights into the impact of DIY practice at social and home infrastructure levels. A similar approach has been taken by Pink and colleagues [2013] to explore the 'situatedness' of energy monitors within the home, as a place where people, things and resources are entangled [Ingold, 2007]. By drawing parallels from the process of domesticating animals and plants, Pantzar [1997] defined domestication of technology as the reorganization and mastery of the technology through continuous care and maintenance.

Previous studies showed that for any technology to be domesticated, or successfully adopted within the home, its deployment should fit rather than disrupt the house's infrastructure defined at stuff, space and service layer [Tolmie and Crabtree, 2008]. This can be achieved if changes to the house are restricted to its moveable objects, (i.e., the stuff layer), rather than the spatial layout of walls, doors and windows (i.e., space layer) or the utilities and communication infrastructures (i.e., service layer). The changes to the space or service layers are kept minimal as they are particularly taxing and disruptive.

Tolmie and colleagues introduced the concept of digital plumbing [2010] to describe the work of setting up and maintaining the home network, needed for introducing new technology in the home such as an Internet hub, a new TV, or media PC, and digital housekeeping [Tolmie et al., 2007] for organizing and backing up digital resources such as collections of music or photos. They showed that setting up is carefully planned to accommodate, respect and support the existing infrastructure and domestic routines at both the physical and social levels. A similar argument has been proposed by Dourish [2015] in his discussion of the Internet, highlighting the importance of the physicality of cables and connectors but also of their socio-material arrangements.

To summarise, the socio-material aspects of home infrastructures are brought to the foreground when new technologies are deployed at home. In such cases, people tend to domesticate technologies through minimal digital plumbing or disruption to the home infrastructure and household routines, particularly resisting disruptive alterations to the space or service layer. We know little, however, about the impact on home infrastructure of technologies intended to be disruptive, such as DIY monitors and their potential to trigger energy saving practices. 
Exploring DIY Practices of Complex Home Technologies

$39: 9$

\section{STUDY METHODOLOGY}

\subsection{The Two Green Communities: Energy Monitoring and Energy Coop}

For this research project, we engaged with two UK communities of green enthusiasts. The first group, Monitoring Energy (names changed to preserve anonymity), is an online community of amateur and professional engineers interested in supporting the understanding of energy use and the challenge of renewable energy. The community was founded in 2009 with the aim to design and build an open source energy monitoring technology which is powerful, affordable, compact and easy to install. In 2011, the two founders of the Monitoring Energy community have launched a startup providing a DIY kit for supporting non-experts to build their own DIY monitors.

The second group, Energy Coop, is a small local community of about 100 green enthusiasts, founded in 2008 with the aim of reducing energy demand and carbon footprints in residential homes. Energy Coop's interest in open source hardware led its founders in 2011 to forge links with Monitoring Energy community for adopting the DIY kit. In 2013, this partnership led to a joint project initiated by the Energy Coop. This project consisted of a series of hands-on workshops, organized and run by the Energy Coop founders with input from the Monitoring Energy founders, with the aim of helping its members assemble a DIY monitor. At the start of our study, this project already consisted of two weekend long workshops and fourteen monthly sessions to meet up and share skills. Workshop participants were also directed towards the online tutorials on Monitoring Energy forum, designed to support people with no electronics or programing experience. Here is a quote from the main organizer with respect to the skill set available in the workshops: "I think in the build days, we were 80\% deep green type people and about 20\% electronic people" [P9]. The workshops took place at MadLab, a three-storey building located in the Northern UK, in an area that has undergone continual regeneration over the last ten years. During this period it has earned a reputation as a bohemian, creative and free thinking place attracting designers, hackers, makers, innovators and artists.

\subsection{The System: DIY Monitor}

The DIY kit consists of sustainable low cost, low power electronics, i.e. wireless sensor infrastructure, a Raspberry $\mathrm{Pi}$ base-station and a wireless graphical LCD display. In addition to electricity, temperature and humidity sensors, the system infrastructure can be reconfigured to include other measurements such as solar power generation, and potentially gas and water consumption as well as indicators of air quality. The system is not able to track individual appliance use, although it provides the total amount of energy used at a given power. The base-station receives data from the sensor infrastructure every second and uploads them to a cloud-based server. The LCD unit displays real time power consumption and generation, as well as room temperature. The DIY monitor allows the customization of the web interface, so that people can select, move about and resize their preferred data visualizations of real time and historic power which can be explored at different time scale. The interface is available on PCs, laptops and mobile devices and people can share it publicly on the website. The DIY kit consists of a mixture of surface mount boards

and through hole electronics requiring manual assembly, soldering and firmware loading (Fig. 1). 


\subsection{Method}

This paper aims to explore the end users' experience of assembling the DIY kit and of using the built DIY monitors in their homes, as well as monitors' impact on the home infrastructure as the ecology of people, smart objects, and practices. We conducted interviews with 18 participants, nine members from Energy Coop (P1-P9) and nine from Monitoring Energy (P10-P18) to explore their experience of assembling the DIY kit and of using the DIY monitor in their homes.

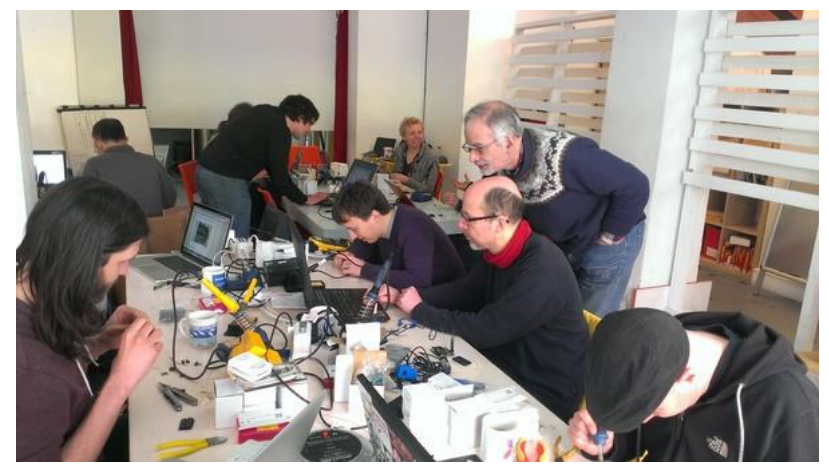

Figure 1. Hands-on DIY monitor assembling workshop at MadLab

First, we engaged with the founders of a local green community, and with their help we recruited 9 participants who shared their specific experience of assembling and using the DIY monitor. Second, to further our understanding of this experience and extend the sample size, we engaged with the online community from where we recruited an equal number of participants who assembled and used the DIY monitors, some of whom have also been involved in building the DIY kit.

In the online community we first contacted the founders and used their in-depth knowledge of this community to identify additional interested participants. In this way, we ended up with a larger sample of 18 participants, sufficient for a critical case sampling and for achieving both informational redundancy and theoretical saturation [Sandelowski, 1995]. Participants were recruited through open invitations on MadLab's project web site and Monitoring Energy's online forum, and subsequently through snowball sampling. We now describe the demographics of each subgroup of participants.

Since Energy Coop is a local community to one of the researcher's, we performed face to face interviews in participants' homes. We interviewed 8 men, 1 woman (and 2 spouses as two interviews involved couples) (mean age 45, range 31-69) ensuring that the maker of the DIY monitor within each household was present. All 9 participants deployed the monitors in their homes and engaged in their long term use from a couple of months to five years, and in average for 18 months. They belong to middle class with occupations such as architect, scientist, teacher, engineer, or consultant, and live in single-family homes with their partners; half have children at home (all below the age of 10). All participants have used commercial energy monitors in the past, usually offered free of charge by energy providers. We also interviewed three of Energy Coop's co-founders, i.e., P6, P7 and P9. Each participating household was rewarded with a locally sourced organic vegetable box, delivered by the interviewer.

Interviews with the members of the online Monitoring Community took place via Skype (9 male) (mean age 43, range 26-59). All participants had deployed the DIY 
monitors in their homes and used it for at least a year (two for 12 months; four for 18 months, and two for over five years). These interviewees belong to the middle class with occupations such as entrepreneurs, managers, and engineers. Most participants live in single-family homes and two have children at home (below the age of 13). Again, all participants had also used commercial energy monitors, usually offered free of charge by energy providers. In terms of professional expertise, four have university degree in Computer Science or Electronic Engineering, and two in Physics, while the remaining two have pre-university qualifications. Among participants, we also interviewed Monitoring Energy founders, i.e., P10 and P11 Given that these two participants had developed the DIY kit over the last 6 years, they have acquired in depth technical knowledge. The interviews with the members of the online community took place via Skype rather than face to face as their homes were located all across the UK. We decided to reward each participant with an Amazon vouchers worth $£ 10$ and delivered by email. This addressed the increased cost and the logistic challenge of delivering locally sourced organic vegetable box to these participants.

The aim of the interviews was to explore end users' practices of building and using high tech electronic technologies in their homes. We conducted semi-structured interviews with participants from both communities, each lasting at least an hour. Within this paper we describe a subset of the findings focusing exclusively on the qualities of the DIY kit and the DIY monitors, and their impact on the home's sociomaterial infrastructure. For this, we inquired about the motivation for engaging in the practice of high tech DIY and the values underpinning it, participants' specific experience of assembling and using the DIY monitors, and DIY monitor's impact on the home. We asked participants: "How do you describe the monitor", and "What was your experience of working with the DIY kit". We also explored the rationale for building the DIY monitor: "Why did you choose to build the monitor" and about the process of building it. We asked participants to recall in detail their experience of assembling the DIY monitor and of installing it in the home, and for the founders of the online community, their experience of making the DIY kit. We also invited reflection on the DIY monitor and participants' engagement with it: "Did you learn anything new from building and using the monitor" and "How does it compare to other energy monitors that you have used". Not at least, we inquired about DIY monitor's impact on household routines and home infrastructures: "Did you notice any new or different household routines?" and "Please describe the deployment of monitor in the home". The face to face interview concluded with a home tour where people described their daily routines and typical consumption behaviors.

The majority of the interviews took place within 18 months from the building of the DIY monitor, thus allowing the exploration of its use over a duration longer than typical engagement with commercial monitors [Cooper, 2004]. All interviews were recorded, generating over 20 hours of audio that were fully transcribed.

We employed a qualitative approach because it is the best suited to explore the understanding of an experience from the perspective of those experiencing it [Vaismoradi et al., 2013]. Among the various qualitative research methods, thematic analysis was chosen because of its ability to answer the research questions relevant for our study, and its flexible approach to provide rich, nuanced, and complex account of the data [Braun and Clarke, 2006]. Often used in HCI research, thematic analysis is also considered a robust approach for an introductory study on a novel phenomenon such as the one we explored [Vaismoradi et al., 2013]. 
The data was analyzed using an iterative hybrid analysis which allows key relevant concepts from the existing literature to be integral to the deductive analysis, while allowing also for themes to emerge from the data using inductive coding [Fereday and Muir-Cochrane, 2006]. We started generating the initial codes for identifying interesting data relevant to our research aims. Such codes include concepts identified in the state-of-the-art such as different types of DIY practice, i.e., making and repair, different types of DIY kits, and their qualities such as modularity, blackboxing and depunctualization. In addition, the identified data-driven codes include motivation, engagement, attachment and additional qualities of the DIY monitor such as being open or resisting obsolescence. Once the interviews were coded, we iteratively searched and revised the themes by identifying also the coded data supporting them and ensuring that the data within each theme is more cohesive than the data between themes. This process has led to three themes (each with several sub-themes) as described in the Finding Section: breaking open the blackbox, unlimited exploration, and imbuing personal value through handcraft. The identified themes were discussed extensively between researchers to reach consensus.

To ensure rigor of our qualitative inquiry, we adhered to Padgett's principles [1998]. Thus, we conducted lengthy interviews and engaged with the local community over a couple of months, triangulated from two sources of data, i.e., the two communities, iterated the data coding process and discussed at length between us. While the generalization of findings from qualitative studies to other contexts that the one investigated is an issue of ongoing debate, we agree with Lewis and Ritchie's argument [2003] that such generalization is possible as long as the conditions are clearly specified. We argue that our findings grounded in complementary sources and clear data analysis support the thesis that the qualities of the DIY kit and DIY monitor may also hold true for other high tech DIY technologies such as those developed through Arduino-like open source prototyping platforms. Future work in these different contexts is needed to confirm this wider inference and theoretical generalization. We now report on the findings.

\section{FINDINGS}

Data analysis highlights three themes, each one further described: breaking open the traditional black box of complex home technologies, indefinitely exploring and experimenting with the DIY monitor's components, as well as imbuing personal value throughout its making.

\subsection{Breaking Open the Black Box of Complex Home Technologies}

This theme reveals the challenges of hardware which is not open, and in particular of ready-made energy monitors as black boxes which cannot be explored or tinkered with. It outlines the journey of the Monitoring Energy founders to develop the DIY kit by reverse engineering commercial monitors. Breaking open the black box supports not just the making of the DIY kit, but also end users in their DIY practice of assembling the DIY monitor and the learning it entails.

We start by describing the rationale for the development of DIY monitor and kit. This was grounded in the Monitoring Energy founders' interest in understanding and reducing energy consumption, and the desire to overcome the experienced limitations of commercial monitors such as control over the generated data, lack of remote access, and limited interaction with and management of the archived data: 
Exploring DIY Practices of Complex Home Technologies

39:13

"In 2009 I had a conventional energy monitor but it wouldn't connect to the internet and I couldn't get out the data in the way I wanted. At that time, there was the whole thing about the green house starting and there was the project with $3 D$ printing and there was a huge amount of excitement and development going in this open hardware. [and started to] look into how I could measure my electricity [and] documenting the initial energy monitor" [P11].

This indicates the founder's value for the maker movement and potential for the innovation taking place in open hardware at the time. The project was also inspired by the founders' interest in renewable energy, and the awareness of a demand for a monitor that could also track renewable energy generation: "At that time we worked on several projects like building small wind turbines and running solar panel workshops. And what we found is they were missing some technology, some monitor for these renewables" [P10]. The open source energy monitor is now a commercial product which can be bought either fully assembled, or as a DIY kit. Both versions are open source, but the latter costs less. We now describe how the kit was put together, and the main challenges of this process. Findings indicate the importance of breaking open the black box of complex home technologies occurring both in a literal and metaphorical sense.

From commercial monitors to the electronic DIY kit

Our interviews with the two founders of the Energy Monitoring community (P10 and P11) show that the process of designing the kit started with breaking open the enclosure of a commercial monitor: "I opened up [a commercial monitor] but I couldn't understand how it worked [...] isn't open from the start and they don't provide you with any documentation to go along with those circuits" [P11]. This quote indicates more nuanced enclosing practices of commercial electronics in order to prevent tinkering. These extend to internal enclosing to cover key components, and to a lack of documentation for making sense of the overall components and their interconnectedness. To overcome this challenge, P10 and P11 researched online for such documentation which they sourced from both private sector and academia. For example, they found a manufacturer of microcontrollers, describing their use in various applications including energy monitoring: "We used a part of that circuit for the assessing stage" [P11]. They also used the outcome of a university research project which "showed very well how to measure, how to do the calculations on the power measurements in order to get a sample of the signal to calculate power" [P11].

Despite such support, an ongoing challenge of retrieving needed technical information was the inability to ask the right questions: "I always found it hard to get some information because sometimes you don't know which questions you should ask" [P11]. This suggests the value of a community of practice where the context of the problem domain is already shared, and the expertise can be easily sourced. This indeed happened later when the online community became established: "that's lots of people in there that have considerable experience, a lot more than two of us [...] sometime when we are stuck, we'll ask on the forum or by email" [P11]. Reflecting on the information needed to explicitly support reverse engineering, and more broadly tinkering, participants noted: "If [commercial monitors' producers] provided a circuit diagram describing how the circuit board works, and if they labelled all the components, and values that would make it open hardware and something that you could understand" [P11]. While this richness of information is not readily available, it is exactly what the Energy Monitoring community has successfully put together. 
From electronic DIY kit to end user's DIY monitors

Most participants noted the value of physically accessing the DIY monitor's inner components. They described how the DIY kit materializes a deconstructed version of the DIY monitor, which can be seen, and whose components can be touched, manipulated, altered or connected: "you put all the components in [and] understand the basics of electronics [...] shaping the electrical signals and it's really interesting to see how it works inside" [P7]; or "there are many products in our houses that you rarely see in that deconstructed stage. [...] it gives you control to adapt and customise the monitor" [P6]. These quotes indicate the value of the DIY monitor as an open box, and its quality of being kinaesthetically touched, moved and altered, as well as broken down in constituent parts with distinct functionalities.

\section{From functional to structural models of energy monitoring}

A quarter of participants noted the understanding of how energy monitors work that comes from the deconstructed representations of the DIY monitor, and from handling its basic components: "it was interesting because you built it right from the bottom up; you put all the components in, which gives you the grounding to see how it works inside" [P7]. As a result, most participants acquired a richer understanding of the energy monitors as complex devices: "I was just intrigued as to what an open source energy monitor was, and just getting behind the black box unit to have a better understanding of how these monitors work and what they were doing" [P3]; so that "if it breaks you can understand why" [P7].

As indicated in the last quote, such understanding can further extend to fixing the DIY monitor over its lifetime: "there is something in learning a new skill and building something with your own hands. You're able to understand and fix, which I think people find a little bit lacking in the modern world" [P9]. Such understandings also suggest that building the DIY monitor supports the development of structural mental models containing information about the internal structure of a device, how it works and how it may be fixed. This is a significant outcome since people tend to operate such devices through limited functional models [Mellis and Buechley, 2014; Pierce et al., 2010] and they seldom acquire structural models of complex technology [Norman, 1983]. The foundation for these structural models was laid out when participants learned about the inner guts of the DIY monitor: its basic components and how they come together, and when they explored how to extend the monitor. Here they opened their eyes to the realm of possibilities of integrating available sensors with the built monitor as outlined below.

\subsection{Unlimited Exploration}

The second theme extends the concept of playful exploration with the DIY monitors across the temporal dimension and imagined possibilities. This theme captures the DIY monitor's quality of being tinkered with either in the present, the future, or the imaginary. As further outlined, such exploration focuses on new types of sensors for extending DIY monitor's capability of measuring data. It also describes the challenges of deploying these sensors in the home's IoT around the DIY monitor.

The value of electronics DIY practice for supporting creative play and experimentation has been previously suggested [Bakker and Hollander, 2013; Kuznetsov et al., 2013]. But while previous work has focused on the present, our findings indicate that this quality is enduring, extending beyond the making of the DIY monitor and into the future customization. For example, seven participants mentioned how the DIY monitor allows imaginary experimentation, both for the 
planned and near future: "once I've got the monitor up and running I would expect to continue to add to it and tamper with it" [P8], or for the distant future: "It's not what it has now, but what it could have. [The monitor] has that latent capacity which most technology rarely do [...] as we have children and our lifestyles change because of our age, the monitor data will allow us to track that change" [P6].

Such experimentation is triggered by changes in family life both foreseen and unforeseen, and the evolving needs of the household: "now with the baby there's a lot more bath water used. So having a cheaper gas bill will be beneficial" [P12] or "The sure point is that energy prices are going to go up. So anything I can do to reduce our energy bills it's a long-term investment [which] will help my retirement" [P14]. More importantly, these possibilities of customizing and adapting the DIY monitor are not restricted or exhaustible, so that the experimentation could be endless: "it is really infinitely playable around with" [P7].

We now describe the content of this exploration. It tackles a variety of sensors that could be deployed in the home, targeting not just electricity consumption but also the generation, storage or management of electricity, as well as the consumption of other natural resources such as water or gas. We identified three forms of exploration which consist of identifying and cataloguing new sensors and their performance, exploring sensors' feasibility for future deployment in the home, and developing a network of sensors in the home.

\section{Identifying and cataloguing new sensors and their performance}

An interesting finding is that about two thirds of participants described their engagement in the exploration of new sensors. Apart from changes in the household's needs due for example to the arrival of a baby or retirement, another trigger for participants' engagement in this exploration of new sensors is a specific issue with the current living conditions: "I am interested in humidity sensor because we've got a slight damp problem upstairs" [P1].

Another motivation is to use the DIY monitor to reduce consumption of different natural resources: "the gas sensors arrived in the post this morning [so that I could] monitor the gas in the kitchen. I will look at their capabilities and quality" [P15]. Since such triggers are individual and idiosyncratic, the exploration of new sensors is usually performed individually. However, most participants are often motivated to share their findings on new sensors with others, or through the online forum.

Beside the individual search for sensors, the Energy Coop local community has also developed a more structured process for coordinating this exploration, mostly driven by its founders: "there's a limited number of plugins available [within community] while others are being tested. [We are exploring] satellite humidity monitors [which we] could place within walls [P6]. This process of testing targets both performance as well as the fittings to different home infrastructures: "[Energy Coop] tests the cheaper [commercial gas meters]; there are about 20 types of gas meters, but you have to have those that are specific to your meter" [P7].

This archive of documented hardware guides people's exploration of best available sensors appropriate for their needs and house infrastructure. In this way, it reduces the searching space to a more manageable size. Interesting here is the focus on testing both the performance and the fitting within the home. The latter is further detailed. 
Exploring sensors' feasibility for deployment in the home

An important concern regarding new sensors is their compatibility not only with the DIY monitor but also with the household infrastructure. This requires developing an appreciation for the complexity of installing the DIY monitor in the house. Whereas home technology tends to be domesticated [Tolmie and Crabtree, 2008] in order to fit into the household infrastructure with minimum disruption, our findings suggest that the DIY monitor requires that the house itself also changes to accommodate both the DIY monitor and the subsequent energy reduction measures whose impact is measured by the monitor.

Such changes affect household internet network and electricity infrastructure, as well as house's space layer of walls, floors, windows and roof. For example, five participants mentioned changes to the internet router: "the monitor made me more aware of the consumption of the computer, and so I changed the router at some point" [P2]. The changes targeting electricity infrastructure were more difficult to implement, but seriously considered: "The electricity meter cupboards are in the hall, but since there is no socket, [the wire] would have to go down across the floor which would be a trip hazard. Or, I can have a socket installed near the meter cupboard, which would be a more sensible solution" [P5]. This indicates the DIY monitor's value in prompting the exploration of the challenges of electricity infrastructure, and exploration of solutions. Changes to the house walls, floor, windows or roof were made to optimize or reduce energy consumption, or to generate energy. These include for example cavity insulation, triple glazing windows, underfloor heating, hot water panels, or solar panels. Additional changes were made to install sensors in different home locations. This is an important finding indicating the value of the DIY monitor as a hub for a home internet of things, which is further detailed.

Developing a network of sensors in the home

As indicated by almost all participants, the most common location of the DIY monitor is on the kitchen's or living room's wall. This central location reflects an equal central role that the DIY monitor is granted in the household's daily life: "My goal is to have a single Raspberry Pi computer jointed to the DIY monitor for all of the energy and temperature monitoring" [P17]. Most of participants mentioned that the preferred method for developing their network of sensors involves scaling up the number and types of sensors that can be attached to the DIY monitor: "I monitor electricity and temperature. I have a temperature sensor in the kitchen; one partly powered in the bedroom, one directly connected to the DIY monitor under the stairs which registers outside temperature, and a fourth one in the studio" [P13].

The extension of the DIY monitor with new sensors is often accompanied by the extension of its web interface so that the gathered data can be explored: "you can customize your own dashboard [to have] a graph of electricity and temperature in your house" [P10]. Most of participants have performed some basic interface customization, and although more sophisticated customization requires additional technical skills, about half of participants described their interest to attempt it:

"II customized my dashboard] to show the total solar power [broken down for each of my two solar panels]. I also wanted to add a page to see the charge rate for the [electric] car so I copied the code and changed it a bit. It didn't work properly so I asked [for help] so I kind of got there right now" [P13].

In addition to sensors, the top four most technically competent participants from the online community also experimented with actuators for turning on and off appliances on demand: "My ultimate goal is to have the energy monitoring controlling the energy 
usage of the flat" [P18]. This interest in house automation is particularly interesting as it extends beyond monitoring electricity consumption but monitoring also electricity generation, management and storage.

For example, one participant mentioned extending the DIY monitor with the capacity to intelligently divert electricity by disconnecting and reconnecting appliances. The aim here is to ensure that the green electricity generated by the solar panels is consumed within the house rather than being returned to the grid: "I could extend the monitor quite easily because I have a wired house and smart sockets, and say when the [generated] power is between this range, switch that off" [P14]. Finally, a few participants mentioned interest in storing the generated electricity for future use within the home, either through battery-powered devices such as laptops, or through electric cars: "[We have two electric cars] charged with the solar PV excess and then at night we give it back to the house. In this way, [the cars are also] used for energy storage" [P13]. This suggests an interesting appropriation of the electric cars as house batteries.

We now turn our attention to the impact of the unlimited exploration on end users. Deploying the DIY monitor in their homes has meant that often the DIY practice continues to ensure that the monitor is repaired when needed or customised as desired. As a result of monitor's capacity to future-proof itself, ten participants envisaged long-term engagement with the DIY monitor and with the issue of energy consumption: "the monitor keeps opening up possibilities of what you could add or what you could do, and if you've got the inclination to do that, it can make you in the end more sensitive to the issues around energy and reducing its use over time" [P3].

The sense of agency and control experienced while shaping a unique device able to meet people's current and future energy needs, leads to a cherished device which resists obsolescence: "how you adapt and customise the energy monitor, gives you control; it's not something that becomes obsolete once it comes to the end of its lifetime, it's something that you can add to, take away, and it's that adaptability which I think really sold us to the energy monitor" [P6]. The DIY monitor's potential to adapt to household's future needs strengthens people's long term attachment to it. Previous work has shown that people's disengagement with electricity monitors is triggered by limited support for new learning goals [LaMarche et al., 2012; Schwartz et al., $2013 \mathrm{a}, \mathrm{b}]$. Our outcomes extend this by showing that the adaptability of DIY monitor has the potential to support new learning goals, and subsequently engagement.

\subsection{Imbuing Personal Value through Handcraft}

The third theme captures end users' DIY experience: the emotions and meaning associated with the DIY monitors. It outlines how this practice driven by environmental values imbues personal meaning in the making of monitors. Such meaning is described in relation to embodied meaning developed through handcrafting, and its associated emotional engagement.

Value-driven DIY practice

We start by highlighting the end users' motivation for engaging in the DIY monitor practice. Prior work suggested that DIY practice is either for pleasure or for serving functional roles [Hertz, 2011]. Our findings indicate that the majority of participants' motivation is foremost value-driven, subscribing to the key values of the environmental movement for sustainable practices of energy production and consumption. In particular, the quality of the open DIY monitor supports an ideology 
towards localizing energy generation, as highlighted by three participants. This agenda of emancipation from corporate energy providers targets also the democratization of energy consumption, as eloquently described by one of the founders of Energy Coop: "In the future, energy production will be less around big infrastructure, distant from the house and more around the house through solar panels or local wind, more community scale energy. [So] if communities can work together then it's not just a rich few using energy all the time but there can be better quality and access to energy for more [through] open source monitors which are not owned by a big energy company". Core to this agenda is local and renewable energy production and increased independence: "It's a local issue: generating and using renewable electricity on your roof" [P12].

\section{Embodied Meaning}

A second theme relates to the personal value imbued into the DIY monitor, confirming findings on the value of craft in imbuing meaning [Sas and Whittaker, 2013; Sas et al., 2016], Findings suggest that handcrafting offers a space where fragile components are carefully handled to be manually assembled or dissembled. Although these components may be seen as lacking personal value, this was far from true: "[The DIY kits] have their own embodied energy because someone has crafted these circuit boards or there has been thought put into them. That's something that has its own inherent value, not seen as disposable" [P6]. This quote is illustrative for almost a third of participants, suggesting that the cost of the DIY monitor is not the only investment that matters.

Equally important, albeit more hidden, was other people's labor in preparing the DIY kit, both for designing, and manually pre-assembling some of its components: "[through the] hand-crafted aspect you do impart some personality or memory that doesn't exist in other objects you just purchase [...] memory of building and knowledge imparted in that process. I think that's critical" [P6]. This quote suggests that the DIY monitor embodies not only the handcraft quality of the DIY kit, but also the monitor's maker and his or her personal investment of "sweat, sawdust, frustration and satisfaction", echoed also in the DIY practice of home improvement [Shove, 2007]. This goes beyond the pleasure and fun of working with one's hands: "Build your own sounds so much fun [...] as humans we like to build things and get satisfaction out of that, rather than just consuming" [P12], towards deeper emotions leading to a richer, embodied understanding of the energy: "Because electricity is intangible you have no concept of it whatsoever. You just switch things on and you expect them to work [By using the monitor] I have the physical understanding of what $1 \mathrm{~kW} / \mathrm{hr}$ of electricity is in terms of the hot water you can boil in the kettle or how much sun is required to generate that" [P12].

Activities like soldering sensors on the circuit boards, mounting the DIY monitor on the wall of the house, taking it off and opening it to re-solder broken components or solder in new ones involve interaction with materials, inaccessible in both commercial monitors and electric devices in general. For example, a few participants experienced difficulties because of their limited experience with soldering: "I soldered something the wrong way round and had to pull it apart, and others did the same" [P7]. Other participants have soldered on the wrong places: "I made a mistake in my soldering by using one of the other inputs on the board [which] it didn't work and I've also left a dry joint" [P17]. Such bodily interaction with the DIY monitor supports an embodied learning about energy and strong emotional meaning as further described. 


\section{Emotional Engagement}

We define emotional engagement as positive emotions towards the DIY monitor and the energy that it measures. Findings suggest that these emotions may have arisen because of the DIY practice, particularly when we look at the distinction emerging within the households. Here, all the DIY monitor makers showed stronger engagement with the monitor, compared to the rest of the family: "because they haven't gone through the process of building and thinking about it as much" [P3]. This stronger emotional engagement become apparent when participants coordinated and negotiated energy consumption practices with their family members: "I've taken on myself to monitor our own energy [...] I might report to [my wife]: "we used more electricity over the last two days; have we had the dishwasher on twice?" not like a complaint, more like let's find out why" [P5]. In turn, this increased sensitivity towards energy consumption and the negotiation of its understanding with the rest of the family, appears to lead to an overall stronger engagement with the DIY monitor: "The built monitor did encourage you to be much more engaged with the whole question of how you are using energy, than one from an energy company, which you just might put in and whilst you might be getting data it's easier just to forget about" [P3]. For the three participants who become also producers of energy, their engagement in the practices of managing, storing and saving energy was even stronger: "Since having solar panels installed on the house, it makes you always want to use the power when it's being generated. So you might try to put the washing machine on when it's sunny, because all the power comes from your panels. You don't need to import from the power stations" [P10].

\section{DISCUSSION}

Through people's experiences of building or extending their DIY monitors, findings have highlighted four qualities: transparent modularity; open-endedness, heirloom quality, and disruptive quality which account for richer embodied learning of the DIY monitor and energy in general, and people's stronger emotional engagement with both. These qualities have been identified by synthesizing the findings and integrating them with key relevant theories as further highlighted. An important outcome is that the first two qualities characterise also the DIY kit, thus extending the application of these qualities to technologies in deconstructed hardware form. We also discuss how through these qualities acquired during the DIY practice, the DIY monitor also embeds key qualities of things. This is an important outcome, as previous work has shown that complex electronic devices in the home are usually perceived as objects, i.e., commodities easily discarded when they break down instead of being repaired [Pierce and Paulos, 2012; Strengers, 2011; Wakkary et al., 2013]. We conclude with three key implications for design, as well as a reflection on the value of these implications beyond interaction design.

\subsection{DIY Monitor's Qualities}

\subsubsection{Transparent Modularity}

The DIY monitor demands and supports the understanding of its inner workings, but its physical substance comes to the foreground in ways in which everyday technologies never do. We have seen how the DIY monitor's circuit boards, sensors and connection wires offer a perspective of open and deconstructed technology that people seldom experience, and in particular end users. We argue that the DIY 
practices offer fresh perspectives for materializing the ephemerality of the digital, through reclaiming both the visceral awareness of its physical substance and the embodied understanding of its working. Key in this process is how the DIY kit and monitor challenge the idea of blackboxing [Hertz, 2011]. While most technologies are purposefully designed to prevent tinkering, either for protecting novice users [Hertz, 2011; Wakkary et al., 2013] or for preventing infringement [Gillespie, 2006], the DIY kit is purposefully designed both through tinkering and for tinkering. We have seen how the development of this high tech DIY kit is a challenging process as reverse engineering is safeguarded by blackboxing.

Besides the traditional device enclosure, our findings highlight more nuanced ways in which blackboxing occurs. First, it is the blackboxing preventing the visibility of some key components, and second it is the lack of documentation about the building components, their functions and working parameters and how they should fit together on the circuit board. Together, these blackboxing mechanisms contribute to the invisibility of technological devices. At the same time, any effort to develop electronic DIY kits should explicitly challenge each of these barriers to support visibility. We argue that in doing so we help emulate a specific quality of DIY kit in particular, and open hardware technologies in general which we call transparent modularity. Modularity is the ability of a device to be broken down into constituent parts with distinct functionalities. While this is a basic software and hardware development principle, we have seen how in everyday technology, blackboxing obfuscates modularity. A concept which better captures the interrelation between visibility and modularity is transparent modularity: technology's ability to reveal the distinct functionalities of its basic components which can be seen and independently manipulated. Transparent modularity is crucial for constructivist learning [Dewey, 1916], supporting people to construct their own understanding of the DIY monitor through the engagement in the hands-on DIY practice.

We now reflect on these three blackboxing mechanisms and how they can be addressed. For this we propose the transparent modularity of basic components; of their inner workings; and of the assembling process. Building on each other, these three forms of transparency support end user's perception of DIY monitor's basic components (see-through); cognition of its inner workings (know-through); and action of how to bring them together (feel-through). We have seen how, in practice, the seethrough is facilitated by the deconstructed DIY monitor in the form of a kit; the know-through is facilitated by the hardware designs, diagrammatic representations and detailed documentation of its inner working allowing for the development of structural mental models of DIY monitor; while the feel-through is supported by the kinaesthetic experience of following assembling instructions in video tutorials.

While most everyday technologies deny transparent modularity, a few accommodate see-through but less so know-through or feel-through. One such example is the contemporary watch designs with a transparent enclosure allowing the visibility of the mechanical skeleton and the aesthetic of its inner working. The DIY of nonelectric consumption goods also benefits from transparent modularity albeit by a simpler type of transparency.

The historic DIY kits consisting of components of different materials [Gelber, 1999] provide the opportunity to see, know and feel how the outcome product gets assembled. While this ensures modularity, the distinction from electronic DIY is that nonelectronic DIY leads to less interactive objects, with less or minimal inner working, where the components are usually on display and easily to access in the 
assembled product. This means that the challenge to ensure transparency of electronic DIY kit is less of an issue for nonelectronic kits. In the making of the DIY monitor, transparent modularity is key in using hardware components such as Raspberry pi and sensors for building its physical form. Findings also show that transparent modularity characterizes both the DIY kit, but more importantly the DIY monitor as complex technology which can be made and re-made.

\subsubsection{Open-endedness}

Another important finding is that transparent modularity is an enduring quality throughout the entire lifecycle of the DIY monitor. This in turn supports openendedness which we define as DIY monitor's quality to be perceived as a work-inprogress, indefinitely customizable, continually evolving and never completed. This quality is in sharp contrast with that of everyday technologies which, as outcomes of the dominant model of design [Ingold, 2009] are completed, and static objects with limited ability to evolve or adapt at hardware level [Marenko, 2014a]. Openendedness partly captures a reconfigurability quality [Blevis and Stolterman, 2007] or digital devices' ability to be updated instead of disposed of.

Our findings also confirm Vardouli's [2015] view, drawing from Ingold's [2009] theory of making that the boundaries between user and artifact cannot be predefined, as they emerge through the process of use. Thus, users are not passive consumers of artifacts or enacters of the scripts embedded in artifacts, but active performers of ongoing improvisational tasks, or makers of use. In addition, we have shown that open-endedness also enables the blurring of the boundaries between the artifact and end users as both the makers of the artifact and makers of its use, by allowing their continuous engagement in the re-making. This further extends Ingold's [2010] argument on the value of user-centric view, where the boundaries between designer and user become blurred as they both perform creative acts of making, to the context of end user development. The user-centric view states that the use is negotiated and innovative, as an open ended, unfolding process, independent from the design: a situated form of making use, contrasting the other two perspectives: the traditional, design-centric view asserting designer's authority on the predetermined, anticipated use; and communicative view arguing that the use is communicated by the artifact.

Indeed, everyday technologies, albeit rich in functionalities and highly appropriable [Salovaara et al., 2011], once manufactured, it has limited ability to be extended with new functionalities as the end user cannot break them open and modify. Arguably, this also applies to DIY nonelectronic goods which once assembled, lead to completed and static objects rather than flexible and continually customizable ones.

Findings indicate that the open-endedness quality blurs the boundaries between the DIY kit and the monitor, as neither one is completed. This also blurs the boundaries between the design process and its outcome indicating a significant departure from the traditional design process [Storni, 2009]. Through its open-endedness, the DIY monitor is becoming a fluid, incomplete and extendable prototype. These are also qualities of things as described by the morphogenetic model which acknowledges the importance of spontaneously emerging, incomplete, fluid and extendable things rather than predetermined, complete and static objects [Deleuze and Guattari, 1988]. This is an important finding, suggesting that in their making, open hardware prototypes start exhibiting the qualities of things. If they are to be fully things, we need to reflect on what will be the textility of hardware making, and the digital equivalent of "carpenter's following the grain of wood" [Ingold, 2010]. We argue that 
at least in part, such textility is supported by the morphing of an open-ended artifact to fluidly respond to the ongoing needs of its end user. To fully support textility, we may need to explore additional forms of engaging with electronics to allow for more sensuous knowledge of following the material, for example, through tangible or gesture based language for hardware programming [Gubbels and Froehlich, 2014].

The open-endedness coupled with transparent modularity is key in giving both physical and temporal form [Vallgårda, 2014] to complex technology such as DIY monitor. We also argue that the DIY kit qualifies as a meta-design tool because of its potential for continual adaptation. We have seen that open-endedness also ensures the DIY monitor's ability to adapt to both foreseen and unforeseen changes in family's life, and to meet its end user's evolving needs. This ability is the crucial characteristic of meta-design tools, but while open source meta-design tools have been mostly considered with respect to open software [Fischer et al., 2004], our findings extend this quality to meta-design tools for open hardware.

Open-endedness is also crucial for enabling people to experiment with the DIY monitor, confirming the value of creative play in electronic DIY practices [Bakker and Hollander, 2013; Kuznetsov et al., 2013]. The investigated DIY kit exhibits modulation between different types of kits [Hermans, 2014]. If in the initial assembling stage it can be seen as supporting restrictive design (determinate outcome and specific instructions), when morphed into a DIY monitor, the kit can be unlimitedly explored, which makes it a conduit for both open and exploratory design. While both lack instructions, the open design has a determined outcome, and the exploratory design has not. We have seen the generative power of the DIY kit encouraging and supporting people to extend the DIY monitor in a variety of ways. The main types of design contributions that our end users have generated include free hardware designs of the DIY kit, catalogue and library of sensors, their characteristics and performance, interface customization; scaling the sensors' number, types, and deployment locations in the home, as well as changes to house infrastructures. In addition, some of the members of online community have engaged in the deployment of actuators for home automation. This impressive range of outcome demands more attention to the innovation potential of these communities, and arguably to richer forms of engagement with academia to support them.

\subsubsection{Heirloom Quality}

Another important quality that emerged through the DIY practice is heirloom quality reflecting the value of the handcrafted material. This quality has been first described with respect to DIY cellphones by Holmer and colleagues [2015]. They, however, did not explore how DIY materials can gain personal value, other than by being rare and mastered with finesse. In contrast, our findings suggest alternative ways of making DIY materials personally relevant through the collective's green values and the personal labor which ensures both emotional engagement and embodied meaning.

The heirloom quality also echoes the ensoulment status achieved for example by an elaborate game room because of the time spent to set it up, or by a rice cooker gifted by one's mother [Blevis and Stolterman, 2007]. Blevis and Stolterman [2007], however, did not explore the value of DIY practice for ensuring ensoulment of electronic devices. We have seen that at its core, the making of the DIY monitor is a deeply value-driven practice reflecting environmental values around energy consumption and renewable energy production and around the issue of localizing and democratizing energy practices. Findings also showed that personal labor, both 
others' and one's own invested in materials throughout the DIY practice, is sufficient to imbue them with personal value. The heirloom quality is less relevant for consumption goods assembled from DIY kits, arguably due to the limited effort required in the step by step making of such objects [Gebler, 1999; Mellis, 2015]. In contrast, early DIY kits for electronic products such as radio, just like our DIY energy monitors, were perceived as more difficult, requiring patience and workmanship [Mellis, 2015].

Although the DIY monitor does not display artisanal qualities, which would require expensive material and handcrafting expertise, this may not even be needed. Instead, only known to the maker, the DIY monitor tacitly embodies the sweat, blood and tears of learning the DIY craft. It also memorializes them through the traces of the wrongly soldered parts. Hence the material wears the scars of all the trails and errors which make it even more personal and valuable, resembling Rosner and colleagues' [2013] reference to the value of explicit traces in hand-made artifacts. All these layers of meanings and values imparted to the DIY monitor shape it as an object with which the maker has an intimate relationship.

Our findings further support the morphogenetic model [Deleuze and Guattari, 1988] emphasizing the embodied design work with the material rather than on material. The outcome of the morphogenetic model is a thing with which its maker has a significant relationship. According to Thing theory [Brown, 2001], in contrast to everyday objects which are unremarkable, invisible, and obsolete prone, things especially handcrafted ones - talk to us in meaningfully rich ways so that the DIY monitor also becomes imbued with thing-like quality of preciousness. Hence it is not surprising that the DIY monitor "speaks" to its maker in ways in which no other person can truly hear. Unlike the unremarkable nature of everyday technology, through their making, the DIY monitors become things of significance. Hence they require emotional investment and elicit attachment, which makes the DIY monitors able to defy obsolescence.

As identified by Blevis and Stolterman [2007], one of digital devices' challenges of achieving ensoulment status in the home is the exposed wires connecting devices and creating clutter. This disruptive quality of DIY monitors is further discussed.

\subsubsection{Disruptiveness of Materiality Infrastructures}

Findings indicate an important disruptive quality of the DIY monitor which elicits changes not only to the house's stuff layer of moveable objects, but also to the space layer of walls, doors, roof and floor, as well as to the service layer of internet and electricity infrastructure. This contrasts previous findings on technology domestication pointing to the minimum digital plumbing or disruption to the home infrastructure and household routines [Tolmie et al., 2007]. While previous findings underline the assumption of the house as a stable system of people and materials which should undergo minimal changes for hosting the DIY monitor, our findings suggest that the house acts more as a flexible ecosystem of people and materials - all to be changed in different ways throughout the deployment and the use of the DIY monitor. The emphasis of previous studies has been however on existing technologies, particularly research prototypes, which participants were invited to take in their homes and engage with.

DIY for home improvement also involves build and electrical work for intentional alteration to the house infrastructure [Atkinson, 2006] demanding intense labor 
[Shove, 2007]. However, there has been limited exploration of how the two types of DIY practices; the making of domestic objects and the home improvement influence each other. This may be because such relationship is less relevant in the context of DIY of nonelectronic goods, as opposed to the DIY of electronic ones. To explore this further, we propose attending to the relationship between domestication and disruptiveness through the lens of DIY practices. As alterations at the house's space and service layer are notoriously taxing and disruptive, then why would people even contemplate installing new sockets or implanting sensors in their house walls?

We advance a rationale around the disruptiveness quality of DIY monitors, which folds within the thingness of the DIY monitor and the emotional engagement, embodied meaning and green values that it quintessentially embeds. As shown above, the DIY monitor is at the central of the house, and its open-endedness is often exploited to extend the DIY monitor towards larger set of interconnected smart objects. Such objects also came into existence through the DIY process; hence they also share the thingness quality of the DIY monitor. Once this personal meaning becomes invested in this domestic IoT it is more difficult to ignore the DIY monitor data which "speak". Unlike most appliances blending within the house to help people affirm their lifestyle, the DIY monitors are purposefully made to challenge the existing lifestyle and current patterns of electricity consumption. Our findings indicate that attending to the complete DIY cycle and its thingness quality is instrumental in injecting the DIY monitor with stronger disruptive qualities through which the changes driven by participatory DIY practice reverberate at individual, social, and house level. First, the DIY monitor's makers undergo significant cognitive changes in their mental models of how the DIY monitors work, and affective changes in their long-term engagement with them. Second, familial relationships and social dynamics are altered by the presence of the DIY monitor in the home and the maker's effort to negotiate others' engagement with it. Finally, the house itself has been changed at the deeper space and service layers to accommodate the DIY monitor. Ultimately, this is a reflection of the symbiotic relationship between the DIY monitor and the house. Our findings support Dourish's [2015] argument for the importance of socio-material arrangements in domesticating home technology. They also suggest that in the case of DIY energy monitors, De Roeck and colleagues' [2012] framework for the creation platform for DIY IoT should be extended from sensors and actuators to account for such arrangements which are concerned with the integration of the DIY monitors into the fabric of the house, and arguably the alteration of the house infrastructure; from walls and floors to roofs and solar panels.

To conclude, our findings indicate that the hardware material of DIY kit and monitor embed key qualities which allow for the sensual experience of holding, making, breaking and fixing them. This in turn has the potential to support richer understanding of their inner working and stronger attachment to the DIY monitors.

\subsection{Implications for Interaction Design}

This section outlines the design principles generated by integrating findings, qualities and theories. This generation process involved both inductive and abductive reasoning [Tavory and Timmermans, 2014], and took place during data analysis and interpretation, as a key heuristic for generating such design knowledge [Sas et al., 2014]. Design principles capture new functionalities of a class of technology [Sas et al., 2014], and our findings indicate the need for supporting transparency of DIY monitor's open hardware, its present and future connectability, and DIY opportunities for stronger emotional engagement. We also reflect on these 
Exploring DIY Practices of Complex Home Technologies

39:25

implications from a DIY historic perspective, and how they may be relevant for the DIY of non-electronic consumption goods. Table 1 provides an overview of the key findings, identified qualities of the DIY monitor, and how these ground our proposed implications for design (right arrows).

Findings

\begin{tabular}{l|}
\hline Breaking open the black box \\
\hline reverse engineering \\
\hline deconstructedview \\
\hline structural mentalmodels \\
\hline Unlimited exploration \\
\hline $\begin{array}{l}\text { customization for present, } \\
\text { future or imagined needs }\end{array}$ \\
\begin{tabular}{|l|}
\hline exploration of new sensors, \\
feasibility and integration in \\
a network of sensors
\end{tabular} \\
\hline Imbuing personal values \\
\hline value-driven: greenvalues \\
\hline embodied me aning \\
\hline emotional engagement \\
\hline
\end{tabular}

Qualities

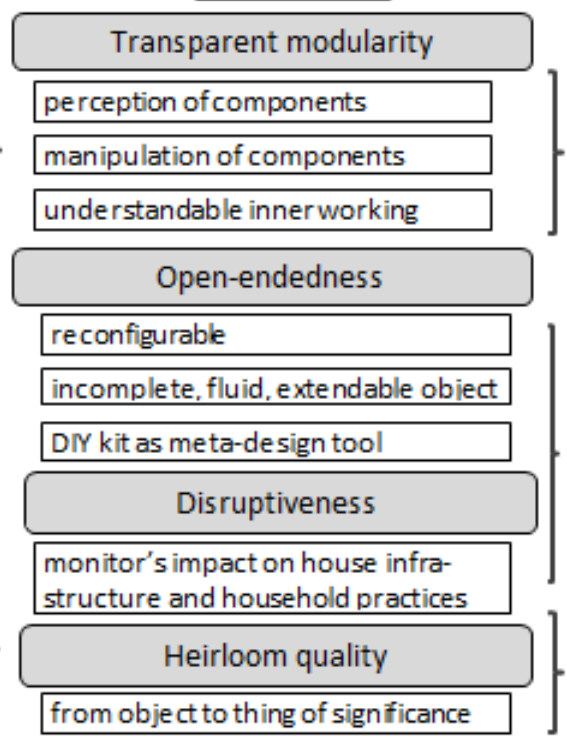

Implications for Design

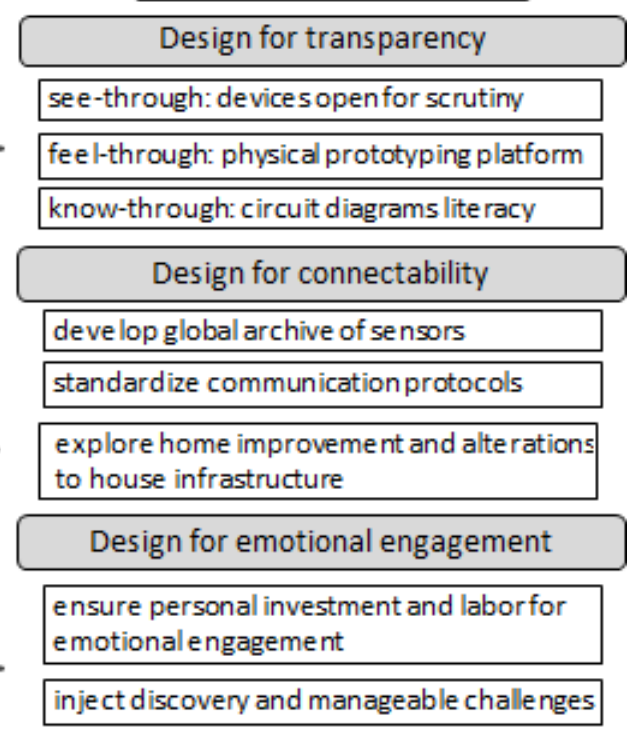

Table 1: Overview of key concepts and their relationship across findings, discussed qualities and implications for design

\subsubsection{Design for Transparency: See-. Know-, and Feel-Through}

Crucial for transparent modularity is the ability to break open the black box of high tech devices. Findings indicate that the electronic components of the DIY kit ensures see-through transparency, the kinesthetic experience of assembling them ensures feel-through transparency, while circuit diagrams ensures know-through of how the inner components work together.

From a historic perspective, the DIY kits for nonelectronic consumption goods also ensure these three types of transparencies, although their simplified inner working is less demanding for the know-through transparency. Arguably, developing and understanding the inner working of the DIY monitor and its circuit diagrams requires higher digital literacy than the instructions required for assembling IKEA shelves. Indeed, our findings highlight significant challenges in developing high tech DIY kits, particularly in the context of end user development. These challenges relate to high level of technical skills which are required, and the robust enclosing of the open commercial monitors preventing tinkering [Hertz, 2011]. But if complex electronic technologies are to be made by end users, then there is a need to support people in developing DIY kits for their making.

This design principle also argues for the value of purposely developing transparent commercial electronic devices which are open for scrutiny allowing end users to understand their basic electronic components in order to develop structural mental models of their inner workings. It also argues for supporting end user development of DIY kits for complex electronic devices through the use of physical prototyping 
platforms. Our findings suggest the value of Arduino prototyping platform in developing such DIY kits, as well as the provision of circuit diagrams for the complex electronic devices that end users aim to deconstruct. Otherwise, the knowledge needed for generating the circuit diagrams is not trivial, and future engagement of academia and end user development is needed for supporting circuit diagram literacy. For example, one can imagine tutorials where common home and personal technologies could be broken open so that their basic functionalities identified and mapped into basic electronic components, supported by existing physical prototyping platforms, together with circuit diagrams for their assembling. Such work could archive the electronic footprint of everyday technologies, which can extend end users' understanding from how things work towards how things can be handmade.

\subsubsection{Design for Connectability: Present and Future}

Crucial for supporting unlimited exploration of the DIY monitor and its continual customization is its ability to be coupled with new sensors and integrated in the current and future socio-material infrastructure of the house. This design implication pertains directly to the ability of the DIY energy monitor to act as the centre of the home's IoT. Three main challenges relate to people's limited knowledge of the available sensors, their integration with the monitor, and the options available for DIY home alterations in order to accommodate the monitor and reduce energy consumption. Each of these is further discussed.

Findings suggest that through deployment of the DIY monitors in their homes, study participants explored their disruptiveness by scaling up the number and types of sensors connected to the DIY monitor and changes to the house infrastructure: spatial layout of walls, doors and windows or the communication infrastructure. Such exploration of the network of sensors in the home, places the DIY monitor at the centre of this IoT network. The main challenge here is participants' limited knowledge of the available sensors, both developed or under development, and their feasibility for being integrated with the DIY monitor. One can imagine a global archive of all available sensors across platforms, so that end users can browse, search, compare, contrast, understand and acquire.

For example, one such initiative is the Open Source Building Science Sensors Project (http://www.osbss.com) hosting documentation on the design and calibration of open source sensors built using Arduino platform. It also host information on sensors' performance gathered through long-term use for the specific domain of microbiology of the built environment. A global sensor archive would host sensors across such domains, as well as generic, domain independent sensors. This design principle highlights an opportunity for academic community to better engage with end user development and maker movement to assist in the development of this global archive, and help reduce end users' searching space for new feasible sensors.

This design principle also emphasizes the importance of standardising communication protocols so that current and future communication technologies deployable in the home continue to support the connectability of the expanding IoT around the DIY monitor. While connectability of digital material has been previously discussed [Vallgårda and Sokoler, 2010], this design principle additionally argues for supporting the exploration of high tech DIY technologies.

Finally, this design principle also suggests the value of supporting end users with a range of options for home improvement in order to reduce household's energy consumption, and with options for cost effective alterations to house infrastructure in 
order to accommodate the monitor and its increasing network of sensors. The former can be supported through enabling end users' access to retrofit programmes, while the latter requires the development of a repository of case studies where people share their home alterations projects by highlighting their costs and measures of success.

While the DIY energy monitor is a good illustration of the concept of IoT, we argue that the design for connectability principle may also hold value for the DIY practice of other high tech personal or home technologies. In a digital world of increasingly interconnected devices, this assumption holds face validity particularly with respect to the standardization of communication protocols, but future work should focus on empirically exploring it.

This design principle may appear particularly relevant to electronic DIY. However, when regarded from the perspective of DIY kit as a meta-design tool [Tetteroo et al., 2013] which allows for continual customisation and adaption of the DIY outcome, we could also reflect on its applicability to nonelectronic DIY. While most of the DIY consumption goods are completed and static objects, a few however are purposefully designed and assembled to be continually adaptable. One such example is the wall shelves developed by Vitsoe, a furniture manufacturer founded in the 1960s, with a vision for sustainability, whose DIY flat-pack furniture kit consists of standard modular units of quality high-grade aluminium that can be configured and reconfigured for different needs. We argue that within the current push for green and sustainable design, this design principle is likely to become increasingly relevant for the manufacturers of nonelectronic DIY kits, and a refocus from built in obsolescence to emotional attachment.

\subsubsection{Design for Emotional Engagement with Complex Technology through DIY}

Previous work has consistently shown that given their limited expertise [Holmer et al., 2015], end users often dispose of broken electronic devices [Pierce and Paulos, 2012; Strengers, 2011] instead of repairing them [Wakkary et al., 2013]. A few studies have shown how the repair practice is delegated to technical experts rather than performed independently at home [Rosner and Ames, 2014]. The value of expressive engagement or digital material's ability to preserve sentiments and histories has been also suggested by Blevis and Stolterman [2007], albeit not in the context of electronic DIY.

Our findings indicate that personal value and heirloom quality can be imbued solely by people's DIY efforts, rather than its expensive materials [Holmer et al., 2015]. This confirms findings showing that when people invest labor in a product, they value it more, i.e. IKEA effect [Norton et al., 2011]. However, we also know that more prescriptive DIY practices of assembling kit's components for the making of nonelectronic consumption goods tend to be performed with limited intellectual or emotional engagement through merely following step by step instructions [Gebler, 1999; Mellis, 2015]. This design principle suggests the value of injecting discovery and manageable challenges in the assembling instructions in order to leverage the emotional aspect of the IKEA effect to the DIY kits of nonelectronic goods.

Our findings also indicate that the value of a made product can further increase if the product is taken care of and repaired. While in principle many DIY artifacts have the potential of embedding things rather than objects' qualities, we know little about if and how complex electronic devices could also embed thingness qualities. Our findings indicate that this can be achieved; they extend the traditional way of 
personalizing technologies or customizing interfaces, indicating instead that DIY hardware customization may offer stronger opportunities for emotional engagement. More specifically, this design principle calls for personal investment and labor in the making of complex technologies in order to support stronger emotional engagement. The electronic DIY kits and DIY practices explored in our study also suggest new ways in which end user's labor can be elicited and supported. The traces of labor and its associated errors could imbue further meaning in the made artifact [Rosner et al, 2013], a meaning which contributes to its status of thing [Brown, 2001].

\section{CONCLUSIONS}

Our study explored the DIY practice within two green communities. We interviewed 18 participants with the aim to reveal key qualities of the DIY kit and monitor. Findings indicate that end user communities motivated by green values successfully engage in the DIY practices of making complex electronic technologies characterized by key qualities such as transparent modularity, open-endedness, heirloom and disruptiveness of home socio-material infrastructure. Findings suggest that such qualities contribute to the making of DIY monitors not as mere unremarkable objects but as meaningful things. Unlike home technologies perceived as easy to discard commodities, DIY monitors support emotional engagement and the knowing of their inner working, therefore resisting obsolescence. Our findings led to three design implications that would support end user development of complex DIY technologies. These include designing transparent open hardware technologies which can be tinkered with, and transparent DIY kits for their making; standardizing communication protocols for the current and future DIY of IoT; and deliberately calling for personal investment and labor in the DIY of IoT.

\section{ACKNOWLEDGMENTS}

This work was supported by the UK Research Council through the Catalyst project, (EPSRC Grant $\mathrm{EP} / \mathrm{I033017/1).} \mathrm{We} \mathrm{are} \mathrm{indebted} \mathrm{to} \mathrm{study} \mathrm{participants,} \mathrm{and} \mathrm{the} \mathrm{founders} \mathrm{of} \mathrm{the} \mathrm{two} \mathrm{open} \mathrm{communities} \mathrm{who}$ enabled this work.

\section{REFERENCES}

Abrahamse, W. \& Steg, L. (2009). How do socio-demographic and psychological factors relate to households' direct and indirect energy use and savings? Journal of economic psychology, 30(5), 711-720.

Atkinson, P. (2006). Do it yourself: democracy and design. Journal of Design History, 19(1), 1-10.

Bakker, C. \& Hollander, den M. (2013). Six design strategies for longer lasting products in circular economy. The Guardian.

Blevis, E. and Stolterman, E. (2007). Ensoulment and Sustainable Interaction Design. Proc. Of IASDR 2007. Hong Kong.

Boden, A., Avram, G., Posch, I., Pipek, V., \& Fitzpatrick, G. (2013). Workshop on EUD for Supporting Sustainability in Maker Communities. In End-User Development, 298-303). Springer Berlin Heidelberg.

Braun V, Clarke V. (2007). Using thematic analysis in psychology. Qual. Res. Psych. 2006; 3: 77-101.

Breitbach, J. (2011). The Photo-as-thing: Photography and thing theory. European Journal of English Studies, 15(1), 31-43.

Brown, B. (2001). Thing theory. Critical Inquiry, Vol. 28, No. 1, Things (Autumn, 2001), 1-22.

Brown, M., Coughlan, T., Lawson, G., Mortier, R., Houghton, R., \& Goulden, M. (2012). Intergenerational interpretation of the Internet of Things. Retrieved May 2016: http://eprints.nottingham.ac.uk/2969/1/Brown_et_al_IIIoT.pdf

Burrell, J. Invisible Users: Youth in the Internet Cafes of Urban Ghana. MIT Press, 2012

Caillot, M. \& Nguyen-Xuan, A. (1995). Adults' understanding of electricity. Public Understanding of Science, 4(2), 131-151. 


\section{Exploring DIY Practices of Complex Home Technologies 39:29}

Cooper, T. (2004). Inadequate life? Evidence of consumer attitudes to product obsolescence. Journal of Consumer Policy, 27(4), 421-449.

De Roeck, D., Slegers, K., Criel, J., Godon, M., Claeys, L., Kilpi, K., \& Jacobs, A. (2012, October). I would DiYSE for it!: a manifesto for do-it-yourself internet-of-things creation. In Proceedings of the 7th Nordic Conference on Human-Computer Interaction: Making Sense Through Design (pp. 170-179). ACM.

Deleuze, G. and Guattari, F. (1988) A Thousand Plateaus. Capitalism and Schizophrenia. London, The Athlone Press; Deleuze, G. and Guattari, F. (1994) What is Philosophy? London, New York Verso.

Devendorf, L., \& Ryokai, K. (2015, April). Being the Machine: Reconfiguring Agency and Control in Hybrid Fabrication. In Proceedings of the 33rd Annual ACM Conference on Human Factors in Computing Systems (pp. 2477-2486). ACM.

Dewey. J. (1916). Democracy and Education. MacMillan.

Dourish, P. (2015, August). Not the internet, but this internet: how othernets illuminate our feudal internet. In Proceedings of The Fifth Decennial Aarhus Conference on Critical Alternatives (pp. 157-168). Aarhus University Press.

Dourish, P., Graham, C., Randall, D., \& Rouncefield, M. (2010). Theme issue on social interaction and mundane technologies. Personal and Ubiquitous Computing, 14(3), 171-180.

Erickson, T., Li, M., Kim, Y., Deshpande, A., Sahu, S., Chao, T., ... \& Naphade, M. (2013). The Dubuque electricity portal. In Proc. CHI, 1203-1212. ACM.

Fereday, J., \& Muir-Cochrane, E. (2008). Demonstrating rigor using thematic analysis: Journal of qualitative methods, 5(1), 80-92.

Fischer, C. (2008). Feedback on household electricity consumption. Energy efficiency, 1(1), 79-104.

Fischer, G., Giaccardi, E., Ye, Y., Sutcliffe, A. G., \& Mehandjiev, N. (2004). Meta-design: a manifesto for end-user development. Communications of the ACM, 47(9), 33-37.

Fox, S. (2014). Third Wave Do-It-Yourself (DIY): Potential for prosumption, innovation, and entrepreneurship by local populations in regions without industrial manufacturing infrastructure. Technology in Society, 39, 18-30.

Gelber, S. M. (1999). Hobbies: Leisure and the Culture of Work in America. Columbia University Press, New York, NY, USA.

Gillespie, T. (2006). Designed to 'effectively frustrate'. New Media \& Society, 8(4), 651-669.

Gubbels, M. \& Froehlich, J. (2014) Physically Computing Physical Computing: Creative Tools for Building with Physical Materials and Computation. IDC '14 Extended Abstracts, Demo Track, Aarhus, Denmark, June 17-20, 2014.

Heidegger, M. 1971. Poetry, Language, Thought, transl. A Hofstadter. New York: Harper \& Row

Hermans, G. (2014). Investigating the unexplored possibilities of digital-physical toolkits in lay design. International Journal of Design, 8(2), 15-28.

Hertz, G. (2011). Arduino Microcontrollers and The Queen's Hamlet: Utilitarian and Hedonized DIY Practices in Contemporary Electronic Culture, 44-47.

Holmer, H. B., DiSalvo, C., Sengers, P., \& Lodato, T. (2015). Constructing and constraining participation in participatory arts and HCI. International Journal of Human-Computer Studies, 74, 107-123.

Ingold, T. (2007). Lines: A Brief History. Routledge, London

Ingold, T. (2010). The textility of making. Cambridge Journal of Economics, 34, 91-102

Ingold, T. (2012). Toward an Ecology of Materials*. Annual review of anthropology, 41, 427-442.

Ingold, T. Making: Anthropology, Archaeology, Art and Architecture. Routledge, London, 2013.

Khairuddin, I.E., Sas, C., Clinch, S., Davies, N. (2016). Exploring Motivations among Bitcoin User. In CHI'16 Extended Abstracts on Human Factors in Computing Systems, 2872-2878. ACM.

Kuznetsov, S. \& Paulos, E. (2010). Rise of the expert amateur: DIY projects, communities, and cultures. In Proc. NordiCHI, 295-304.

Kuznetsov, S., Davis, G. N., Paulos, E., Gross, M. \& Cheung, J. C. (2011). Red balloon, green balloon, sensors in the sky. In Proc. Ubicomp, 237-246. ACM.

Kuznetsov, S., Harrigan-Anderson, W., Faste, H., Hudson, S. \& Paulos, E. (2013). Community engagements with living sensing systems. In Proc. C\&C, 213-222. 
Kuznetsov, S., Hudson, S. E., \& Paulos, E. (2014, February). A low-tech sensing system for particulate pollution. In Proceedings of the 8th International Conference on Tangible, Embedded and Embodied Interaction (pp. 259-266). ACM.

Lagerström, S., Soute, I., Florack, Y., \& Markopoulos, P. (2014, June). Metadesigning interactive outdoor games for children: a case study. In Proceedings of the 2014 conference on Interaction design and children (pp. 325-328). ACM.

LaMarche, J., Cheney, K., Akers, C., Roth, K. \& Sachs, O. (2012). Home energy displays: consumer adoption and response. U.S. Department of Energy.

Lewis, J., \& Ritchie, J. (2003). Generalising from qualitative research. Qualitative research practice: A guide for social science students and researchers, 263-286.

Lieberman, H., Paternò, F., Klann, M., \& Wulf, V. (2006). End-user development: An emerging paradigm (pp. 1-8). Springer Netherlands.

Lindtner, S., Bardzell, S., \& Bardzell, J. (2016, May). Reconstituting the utopian vision of making: HCI after technosolutionism. In Proceedings of the 2016 CHI Conference on Human Factors in Computing Systems (pp. 1390-1402). ACM.

Lindtner, S., Hertz, G. \& Dourish, P. (2014). Emerging sites of HCI innovation. In Proc. CHI, 439-448.

Löwgren, J. and Stolterman, E. (2004). Thoughtful interaction design: a design perspective on information technology. MIT Press, Cambridge, MA.

Marenko, B. (2014a). Material morphogenesis-For an encounter between philosophy and design. Computational Making Workshop -Positioning paper. London: DCC.

Marenko, B. (2014b). Neo-Animism and Design: A New Paradigm in Object Theory. Design and Culture, $6(2), 219-241$

Mellis, D. A. (2015). Do-it-yourself devices: personal fabrication of custom electronic products. Doctoral dissertation, Massachusetts Institute of Technology.

Mellis, D. A., \& Buechley, L. (2014, April). Do-it-yourself cellphones: an investigation into the possibilities and limits of high-tech DIY. In Proc. CHI, 1723-1732. ACM.

Neustaedter, C., Bartram, L., \& Mah, A. (2013) Everyday activities and energy consumption, Proc. CHI, $1183-1192$

Norman, D. A. (1983). Some observations on mental models. Mental models, 1.

Norton, M. I., Mochon, D., \& Ariely, D. (2011). The 'IKEA effect': When labor leads to love. Harvard Business School Marketing Unit Working Paper, 11-91.

Padgett, D. K. (1998). Qualitative methods in social work. Thousand Oaks, CA: Sage.

Pantzar, M. (1997). Domestication of everyday life technology: dynamic views on the social histories of artifacts. Design Issues, 52-65.

Paternò, F. (2013). End user development: Survey of an emerging field for empowering people. ISRN Software Engineering, 2013.

Pierce, J., Fan, C., Lomas, D., Marcu, G. \& Paulos, E. (2010). Some consideration on the (in) effectiveness of residential energy feedback systems. In Proc. DIS, 244-247.

Pierce, J. \& Paulos, E. (2012). Beyond energy monitors. In Proc. CHI, 665-674. ACM.

Pierce, J., Strengers, Y., Sengers, P., \& Bødker, S. (2013). Introduction to the special issue on practiceoriented approaches to sustainable HCI. ACM Transactions on Computer-Human Interaction (TOCHI), 20(4), 20.

Pink, S., Mackley, K. L., Mitchell, V., Hanratty, M., Escobar-Tello, C., Bhamra, T., \& Morosanu, R. (2013). Applying the lens of sensory ethnography to sustainable HCI. ACM TOCHI, 20(4), 25.

Plotz, J. (2006). Can the sofa speak? A look at thing theory. Criticism, 47(1), 109-118.

Reckwitz, A. (2002). Toward a Theory of Social Practices: A Development in Culturalist theorizing. Euro. J.Social Theory 5, 2, 243-263.

Rogers, Y. (2006). Moving on from Weiser's vision of calm computing: Engaging ubicomp experiences. In UbiComp 2006: Ubiquitous Computing (pp. 404-421). Springer Berlin Heidelberg.

Rosner, D. K., \& Ames, M. (2014). Designing for repair? Infrastructures and materialities of breakdown. In Proc. CSCW, 319-331. ACM. 


\section{Exploring DIY Practices of Complex Home Technologies}

39:31

Rosner, D. K., Ikemiya, M., Kim, D., and Koch, K. (2013). Designing with traces. In Proceedings of the SIGCHI Conference on Human Factors in Computing Systems (New York, NY, USA, 2013), CHI '13, ACM, 1649-1658.

Salovaara, A., Hook. K., Cheverst, K., Twidale, M., Chalmers, M., Sas, C. (2011). Appropriation and creative use: linking user studies and design. In Extended Abstracts of CHI 2011, 37-40. ACM

Sandelowski, M. (1995). Sample size in qualitative research. Research in nursing \& health, 18(2), 179-183.

Sas C., \& Chopra, R. (2015). MeditAid: a wearable adaptive neurofeedback-based system for training mindfulness state. Personal Ubiquitous Comput. 19, 7 (October 2015), 1169-1182.

Sas, C., Fratczak, T., Rees, M., Gellersen, H., Kalnikaite, V., Coman, A., \& Höök, K. (2013, April). AffectCam: arousal-augmented sensecam for richer recall of episodic memories. In CHI'13 Extended Abstracts on Human Factors in Computing Systems, 1041-1046. ACM.

Sas, C. \& Khairuddin, I.E. (2017). Design for Trust: An Exploration of the Challenges and Opportunities of Bitcoin Users Proceedings of the SIGCHI Conference on Human Factors in Computing Systems 2017 (in press).

Sas, C. \& Khairuddin, I.E. (2015). Exploring Trust in Bitcoin Technology: A Framework for HCI Research. Proceedings OZCHI Conference 2015, 338-342

Sas, C., \& Whittaker, S. (2013, April). Design for forgetting: disposing of digital possessions after a breakup. In Proceedings of the SIGCHI Conference on Human Factors in Computing Systems, 1823-1832. ACM.

Sas, C., Whittaker, A., Dow, S., Forlizzi, J. and Zimmerman, J. (2014). Generating implications for design through design research. In Proceedings of the 32nd annual ACM conference on Human factors in computing systems (CHI '14). ACM, New York, NY, USA, 1971-1980.

Sas, C., Whittaker, S. \& Zimmerman, J. (2016). Design for Rituals of Letting Go: An Embodiment Perspective on Disposal Practices Informed by Grief Therapy. ACM Trans. Comput.-Hum. Interact. 23, 4, Article 21 (August 2016), 37 pages.

Schmitt, P., \& Seitinger, S. (2009). Plywood punk: a holistic approach to designing animated artifacts. In Proc. TEI 2009, 123-126. ACM.

Schön, Donald A. Designing as reflective conversation with the materials of a design situation. Knowledgebased systems 5.1 (1992): 3-14.

Schwartz, T., Denef, S., Stevens, G., Ramirez, L. \& Wulf, V. (2013a). Cultivating Energy Literacy. In: Proceedings of the SIGCHI Conference on Human Factors in Computing Systems, 1193-1202, ACM.

Schwartz, T., Stevens, G., Ramirez, L. \& Wulf, V. (2013b). Uncovering practices of making energy consumption accountable, TOCHI, 20, 12.

Shove, E. (2007). The design of everyday life. Berg.

Stickel, O., Hornung, D., Aal, K., Rohde, M., \& Wulf, V. (2015). 3D Printing with Marginalized ChildrenAn Exploration in a Palestinian Refugee Camp. In ECSCW 2015: Proceedings of the 14th European Conference on Computer Supported Cooperative Work, 83-102. Springer International Publishing.

Storni, C. (2009). The ambivalence of engaging technology: artifacts as products and processes. Nordes, (3).

Strengers, Y. (2011). Designing eco-feedback systems for everyday life. In Proc. CHI, 2135-2144.

Strengers, Y. (2013). Smart Energy Technologies in Everyday Life: Smart Utopia? Palgrave Macmillan.

Tavory, I., \& Timmermans, S. (2014). Abductive analysis: Theorizing qualitative research. University of Chicago Press.

Tetteroo, D., Soute, I., \& Markopoulos, P. (2013, December). Five key challenges in end-user development for tangible and embodied interaction. In Proc. Conference on multimodal interaction (pp. 247-254). ACM.

Tolmie, P., \& Crabtree, A. (2008). Deploying research technology in the home. In Proc. CSCW, 639-648.

Tolmie, P., Crabtree, A., Egglestone, S., Humble, J., Greenhalgh, C., \& Rodden, T. (2010). Digital plumbing: the mundane work of deploying UbiComp in the home. Personal and Ubiquitous Computing, 14(3), 181-196.

Tolmie, P., Crabtree, A., Rodden, T., Greenhalgh, C., \& Benford, S. (2007). Making the home network at home: Digital housekeeping. In ECSCW 2007 (pp. 331-350). Springer London.

Vaismoradi, M., Turunen, H., \& Bondas, T. (2013). Content analysis and thematic analysis: Implications for conducting a qualitative descriptive study. Nursing \& health sciences, 15(3), 398-405. 
Vallgårda, A. (2014). Giving form to computational things: Developing a practice of interaction design. Personal Ubiquitous Computing. 18(3), 577-592.

Vallgårda, A., \& Sokoler, T. (2010). A material strategy: Exploring material properties of computers.

van Dam, S., Bakker, C, van Hal, J. (2010). Home Energy Monitors. Building Research \& Information, 38(5), 458-469.

Wakkary, R., Desjardins, A., Hauser, S., \& Maestri, L. (2013). A sustainable design fiction: Green practices. TOCHI, 20(4), 23:1-34.

Woodruff, A., Hasbrouck, J., \& Augustin, S. (2008). A bright green perspective on sustainable choices. In Proc. Proceedings of the SIGCHI Conference on Human Factors in Computing Systems, 313-322. ACM. 